\title{
Collegiate Trainees' Committee: guidance for trainees having interpersonal problems with their educational supervisor
}

\author{
Irene Cormac and Geoffrey Marston
}

In many psychiatric rotations, trainee psychiatrists usually move every six months between educational supervisors (consultant trainer). These moves may entail geographical relocation and nearly always involve an emotional relocation for the trainee. Trainees need to acclimatise quite rapidly to different methods of working, training style and expectations from each individual trainer.

It seems inevitable that sometimes trainees will experience difficulties with their educational supervisor. The Collegiate Trainees' Committee (CTC) has found that trainees who find themselves in this position often feel confused about what they should do to improve the situation, without making their working environment unbearable or jeopardising their future careers. This is particularly so for some trainees who may be more vulnerable. These might include newly appointed psychiatrists from overseas, those experiencing social isolation or having difficulties outside of work, for example family matters or mental and physical problems.

The aim of this article is to give some guidance to trainees who are in the process of dealing with such complex issues. It is meant solely for the resolution of interpersonal conflict between indvidual trainees and their educational supervisors. It does not address problems with conditions of service or pay issues, which are best dealt with by the British Medical Association, if you are a member.

\section{Factors increasing the likelihood of problems for trainees}

There are a number of factors which contribute to increased stress in both consultants and trainees. These include excessive workload, lack of resources and additional management commitments. An educational supervisor may experience difficulty in finding adequate time for the trainees' personal and clinical supervision.
This may reduce their function as a teacher and as an appropriate role model within the 'clinical apprenticeship'. This may be especially crucial when a trainee is preparing for an examination. The result may be a lowering of the trainee's morale with mounting responsibility and stress.

Ironically these situations may occur more often with increasing seniority of an educational supervisor. External commitments, such as being medical director, research work or external teaching may, all too often, take precedence over clinical matters. Trainees may decide to suffer in silence rather than risk an unpleasant situation developing.

Sometimes a clash of personality occurs. This may have arisen as a result of poor communication or may be due to underlying factors. Although psychiatrists should be impartial and considerate, their own feelings may interfere with the relationship between educational supervisor and trainee. Issues of racism, sexism, sexuality, religion, jealousy or envy can interfere with the relationship on both sides.

An educational supervisor may forget that empathy, understanding, constructive criticism and unconditional positive regard are essential ingredients in a successful working relationship (Robertson \& Dean, 1997). If the trainee is not performing well, an educational supervisor may feel under more pressure and become hostile towards the trainee without addressing the main problem. Continuous criticism and academic humiliation will dominate the trainee and make them feel more useless and helpless. In this way trainees can easily become the scapegoat in a dysfunctional team.

All these factors may make life very difficult both for the trainee and consultant.

\section{Which is the best path to follow?}

The following four levels of action are graded recommendations, ranging from informal 
approaches to formal complaint procedures. They are only guidelines and each trainee should consider how far along each line he or she wishes to proceed.

\section{Self-appraisal}

The first stage is to think carefully about the root of the problem. Writing your problems and grievances down in a factual and non-personal way, may make things clearer in your own mind. This will then make you more able to decide what to do next. An informal discussion with a discreet colleague may give a different perspective. Is there something about your approach that is adding to the difficulties? It may be useful to find out how your predecessor got on in the post. Did they have similar experiences? This may be all that is needed to help to resolve the issues.

\section{Discussion between trainer and trainee}

It seems obvious that if problems arise, these would be discussed freely with the educational supervisor in the first instance, possibly within the hour set aside each week for personal supervision. Other local trainees might give some suggestions on the most effective way to manage the situation or be able to help with an excessive workload if this is a problem. More senior colleagues (senior registrars or specialist registrars) may be able to advise on the best way to approach the educational supervisor concerned. (S)he may be recognised by the wider trainee body as being difficult to work with. One of the most common difficulties arises over arrangements for the weekly, one hour supervision for the trainee. If supervisors are unable to commit to a particular time each week, it is suggested that trainees book time in advance with the educational supervisor.

\section{Involving other senior staff}

There may be other educational supervisors with whom you feel comfortable to have a discussion about the issues. Some training schemes have appointed mentors, who would be an important person for the trainee to approach. The college tutor or scheme organiser/programme director should be willing to help and might offer to act as an intermediary.

The Postgraduate Training Committee may need to discuss the problem. Bear in mind that the college tutor or scheme organiser may share the information that you have given, unless you specifically ask for confidentiality to be respected. The regional postgraduate dean has overall responsibility for all trainees progress and welfare within the region. Difficulties may be discussed with him/her if they cannot be resolved locally.

In the majority of cases a suitable solution will be found. After all it is the role of educational supervisors, college tutors and scheme organisers to be in touch with the needs of individual trainees and to facilitate their progress through training. If no resolution can be found locally within an acceptable time frame there are more formal channels which can be used. When contemplating using the last level, it is worth considering all the possible implications. Involving external agents to resolve conflicts may well cause resentment, which could impinge on the trainees local reputation and career.

\section{Formal complaint to the Royal College of} Psychiatrists

The CTC representative in your region is available to hear your grievances and would note the issues to feed back at the regular national CTC meetings. Any alarming trends in local training might be identified. The CTC representative would also try to offer advice and support. although they would not be in a position to become directly involved for example as an arbitrator.

The Dean of the Royal College of Psychiatrists, who is currently Professor Katona, should be consulted for advice before revealing the problem more widely in the College. The Dean may be contacted at the College and would consider the best course of action. If necessary, the matter could be taken further, perhaps to the appropriate Royal College Training Committee. However, all other channels should have been explored first.

When writing formally to the College, spend time formulating the problems that have been encountered and describe what has been done to try and remedy them. Write as concisely and politely as possible. Try to be objective and nonjudgmental about the other people who are involved. State the facts and issues clearly, so that your views can be seen as rational and valid rather than reactive or vindictive. If English is not your first language, it may be wise to seek assistance from friends or colleagues.

Throughout these more formal processes trainees can feel isolated and as if they are letting the side down. It is important to maintain the links established at the first and second levels and to keep your college tutor and scheme organiser informed of your actions. Nurture as much support from sympathetic parties as possible. 


\section{Summary}

We recognise that involvement in all of the above processes will prove very stressful. Sometimes the situation may be impossible to resolve entirely satisfactorily. In such cases trainees may wish to reconsider options which would make life more acceptable. Changing educational supervisor within the rotation may be feasible. As a last resort, consider moving to another rotation but one would hope that this situation would not arise.

Remember that trainees may expect certain standards for their training and supervision, in which educational supervisors have a key role to play (Cox \& Davies, 1994). Once these standards are achieved, this will develop a trainees' skills and provide an optimal working environment for both parties. It is a wise educational supervisor who considers the trainee as a professional who will soon become a consultant colleague.

\section{Acknowledgements}

We are grateful to Professor Cox for his advice and to members of the CTC for their comments.

\section{References \\ Cox. J. \& Davies. S. (1994) The Royal College of Psychiatrists Colleglate Trainees Committee 1994. Trainees Charter. Psychiatric Bulletin, 18, 41. \\ RoBERTSON. J. R. \& DEAN, A. (1997) General professional training: consultant supervision of trainees. Advances in Psychiatric Treatment, 3, 347-351.}

*Irene D. Cormac, Specialist Registrar, Reaside Clinic, Birmingham Great Park, Bristol Road, Birmingham B45 9BE; and Geoffrey Marston. Senior Registrar, Brooklands, Marston Green

*Correspondence

\section{Forthcoming in the Recent Topics from APT series}

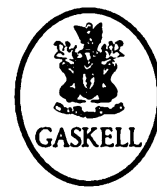

\section{Acute Psychosis, Schizophrenia and Comorbid Disorders}

\section{Recent Topics from Advances in Psychiatric Treatment Volume 1}

The first volume in this new series covers the management of acutely disturbed inpatients, drug and psychosocial approaches to the treatment of schizophrenia, and the problems of comorbid substance misuse and homelessness. There are chapters on risk and childbirth, psychoses in the elderly, and the special problems of identifying and treating psychiatric disorders in those with learning disability. There is also practical advice on assessing fitness to be interviewed by the police, and on preparing medico-legal reports.

The book will be especially useful in conjunction with the College Seminars titles for those preparing for the College Membership Examinations.

\section{Jan 1999, E15.00, 152pp, ISBN 1901242161}

Available from good bookshops and from the Book Sales Department, Royal College of Psychiatrists, 17 Belgrave Square, London SW1X 8PG. Tel: +44 (0)171235 2351, ext. 146, Fax: +44 (0) 1712451231 The latest information on College publications is on the Internet at: $h$ ttp://www.rcpsych.ac.uk 